\title{
Calculation of Product Costs of Dairy Cattle Breeding in Russia
}

\section{Musallyamova M.F.}

Kazan Federal University, Institute of Management, Economics and Finance, Kazan, 420008, Russia

Antonova N.V.

Kazan Federal University, Institute of Language, 420008, Kazan, Russia

\section{Doi:10.5901/mjss.2014.v5n24p403}

\begin{abstract}
This article considers a scheme to calculate the production cost of dairy breeding products in Russia. It offers scenarios to improve it by changing calculation schedule, arranging cost accounts, determining the most reasonable cost allocation bases between joint products.
\end{abstract}

Keywords: calculation, production cost, expenses, cattle breeding, milk, cattle offspring, agriculture, accounting.

\section{Introduction}

Production cost, calculated by the system of accounts is of utmost importance in Business Management System. [1-5]. It serves to provide the most meaningful estimate of inventory value, and in certain cases to set the selling value, to analyze changes in cost effectiveness when changing turnout, to compare profitability of different products, and to estimate their production efficiency, etc. [2].

\section{Theory}

In cattle breeding expenditure accounting items and calculated items do not coincide. Expenditure accounting items are usually groups of animals of mostly the same age which produce the same type of products. Calculated items are all types of products obtained from these animals [4].

The current Russian record keeping system provides cost accounting for livestock management on the control account "Core production", sub-account "Cattle-breeding", setting up a separate sub-ledger subsidiary account for each accounting item. During a calendar year the debit side of the account reflects the expenses on cattle, poultry and fur farming management, the credit side reflecting the target production cost of the derived agricultural products. At the close of the year after expensing capital costs and closing off aggregative clearing accounts there comes the time to calculate the actual cost of production.

In dairy breeding we take the total reproductive management cost for a milking herd less the cost of by-products (dairy sludge) taking into account the actual expenditures connected with its collection. The resting amount of expenses includes cost of milk (90\%) and calf crop (10\%), taking into consideration their actual body weight at birth. Having divided the resulting cost data on certain products production by its total amount, we obtain the prime cost of 1 hundredweight of milk and 1 calf, which constitute the calculation items.

The given procedure has a number of significant shortcomings:

- The schedule of cost accounting (which is usually conducted at the close of the calendar year) does not meet the requirements of current economic environment;

- Analytical accounting does not specify by-products, for which reason the control and quality of cost distribution between by-products get reduced;

- In dairy breeding while identifying one calf at birth the living weight is ignored;

- The net cost of body weight gain in the reproductive herd is not calculated;

- The correspondence criteria used to relate join-cost goods are rather conditional;

- The product self-cost is calculated without regard to its quality. 


\section{Result}

The author conducted a critical overview of the above noted problems and offered the following ways to eliminate them:

1) Prime cost calculation which is conducted at the close of the year makes it possible to carry out only a lookback study of the annual performance and does not provide any short-term information to manage the production, thus hindering control. But unlike a routine analysis, even an in-depth post factum analysis can only detect the failures and losses, but not prevent them.

Moreover, the given procedure does not allow detecting seasonal fluctuations in the product net cost (pasture and farm), does not consider the period of animal's life (dry or lactation).

Therefore we can conclude that the current procedure to account livestock products cost does not provide efficient output or running control and cost analysis. Monthly or seasonal calculation of self cost for animal products will allow us to remove defects.

It is typically considered that the main deterrent of monthly calculation of self cost for animal products is evaluation of the farm feed, produced during the current year and fed to the cattle, by the target net cost. However, if expensing the feed as incurred, we assess them at market (reasonable) value expense, the cost accounting will cause no problems.

2) The by-product in dairy breeding is animal manure. Its value is subtracted from the overall budget for livestock breeding and the resting sum is distributed between joint-cost goods. The manure obtained is assessed according to the amount of expenses on its removal and management, including: the cost of bedding (straw, chaff, sawdust, etc.), depreciation amount of basic tools to clean manure from farms and dung-yards, expenses on its removal from dung-yards, management, disinfection, etc. One of the recent trends in its treatment is recouping waste stream biogas. This trend is still new in our country, but it progresses fast and a number of farms are already introducing biogas units. In response to the increased interest in this farm product we should estimate its efficiency. Recording dung by expenses on its removal, management and recycling, together with its possible price evaluation, will make it possible to achieve the purpose in view and increase control over cost value. In our opinion to tighten the control over cost allocation there is a need to introduce a separate accounting item (subsidiary account) "By-products" in all regions.

3) Use of one head of calf crop as a calculation item, ignoring its weight at birth.

Dairy breeding currently calculates net cost of 1 head of calf crop. But dairy cows' calves can differ in weight (from 20 to $50 \mathrm{~kg}$.). Market price of calves is often set according to their weight. For this reason we think it necessary to estimate the price of calves regarding their actual weight at birth. Therefore the calculation object should be changed; and 1 hundredweight of calf crop should be used instead of 1 head.

But the most debating point is the problem of allocating expenses between different types of joint-cost products.

At various times regulatory accounting documents in Russia provided different methods to calculate self-cost of animal products. For example, in the 1980s in dairy breeding the expenses on reproductive herd management were distributed between the join-cost products by using coefficient method, where 1 hundredweight of milk equaled to 1 , and 1 head of calf crop - to 1.5. To get the total sum of units responsible for cost allocation, these indexes were multiplied by the amount of product. By-products had fixed prices: 1.5 rubles per ton for dung, 2 rubles per item for still-born calves' jacket, etc. [6].

A similar cost allocation method (by relating milk to calf crop and expressing one product in terms of the other) is adopted in a series of other countries. For instance, in Poland $1 \mathrm{~kg}$. of calf liveweight equals to 6 liters of milk, in Hungary 1 hundredweight of milk equals to $14.3 \mathrm{~kg}$. of calf liveweight.

From the 90s onwards management cost of a reproductive herd net of by-product cost is distributed between milk and calves in the ratio 90/10 respectively. This system to calculate prime costs is based on feed stuff metabolic energy and is highly approximate and simplified.

The case is that feed stuff metabolic energy consumption to produce joint-cost animal goods depends on multiple factors, including animal breed; pregnancy and lactation stage; efficiency index; body energy balance: when the balance is positive, the efficiency of using exchange energy to secrete milk is approximately $70 \%$, with the negative balance it equals to $85 \%$ [7]; nutrient composition of animal feeding [8], etc.

And another thing, feed stuff exchange energy as a cost allocation base can be justified with regard to feed consumption as a separate prime cost item. But what the exchange energy has to do with the wages, herd depreciation, basic cattle handling facilities, etc. is unclear. Such a simplified cost allocation to joint-cost products leads to a significant misrepresentation of self-cost information for each product, and hence the level of its profitability. Nevertheless, to run a business effectively and to reach adequate managerial decisions the company's management team needs exact information. 
It is for this reason that the most disputable questions are those of cost allocation between different types of joint products.

4) Introduction of body weight gain in reproductive herds as an additional calculation item

During the whole useful lifespan, animal bodyweight changes when moved to reproduction herd, and consequently change the economic benefits, the organization can derive from butchering and selling (as the purchase price is set in rubles for $1 \mathrm{~kg}$. of live weight). Under standard conditions animals' body weight grows in the course of their lifetime. It is clear that this increase is associated with certain expenses on their keeping. For this reason a number of authors consider it necessary to introduce another calculation item apart from the others already existing in dairy breeding, that of "reproductive herd bodyweight gain", including cost value of liveweight gain in animal value enhancement (fixed assets account). Thus we will not only calculate the end animal product cost more accurately (without transferring expenses involved in liveweight gain to milk and litter), but will also give true and fair information on main herd animals value, as well as calculate depreciation in the sufficient amount to maintain animal reproduction.

However, first, we should bear in mind that changes in animal's live weight throughout its life is a natural process: during the whole period of gestation the cow's weight grows, then drops after calving (to up to $100 \mathrm{~kg}$., including calf weight, afterbirth, amniotic fluid), and later on the cow gets recovered and gains weight again. Second, there are various factors to affect weight fluctuations, such as lactation, diseases, weather conditions, stress, etc., which despite being short-term can have an impact on weighing thus falsifying the data on weight increment either positively or negatively.

Third, recent studies have proved the fact, that a way to increase cow calf productivity is to increase the weight of bred heifer (500-700 kg. after calving) and advanced practices immediately took it on board. Therefore if breeding heifers we aim to get high weight (not fearing obesity), their weight gain while being in the main herd will not be so significant.

Summing up all the above mentioned facts we can say that during the period in herd the cow doubtlessly gains weight, which is associated with certain expenses. Nevertheless, a true physical count is much complicated. In some cases it is not high, and sometimes it can be a negative quantity, that is the reason why we consider it useless to introduce this calculation item.

5) Use of relevant indexes which make allowance for animals' biological peculiarities and technical process

There exist a great many of opinions on the problem of choosing the most appropriate overhead base: to express the offsprong cost in terms of total milk loss resulting from reproduction process [9], to calculate heifer self-cost at birth on the basis of average cost of keeping a cow in inter-lactation period for no less than two months [10], to apportion costs over joint products [11].

Milk and calf production are mostly simultaneous, interdependent, and interconnected processes. That is why it is impossible to adjust fair expenses for each product. Any cost allocated to joint products will be relative.

Net cost calculation can give only approximate results of rather subjective nature. For this reason we consider it more suitable, convenient and effective for daily and tactical management to control revenue expenditures without associating them with the ultimate product cost.

But in some instances (while making certain managerial decisions) data on the product full cost is required (normally, target figures). For that purpose we offer to use the market price (i.e. the prospective sales revenue) for the product with due consideration of its quantum of output as a basis for cost allocation.

Needless to say, that this possibility is not an ideal and unprejudiced cost allocation base to provide accurate information on each joint product cost. As previously stated, milk and calf production form a single process which cannot be divided, that is why it would be fully justified to expect approximately the same return from both joint products. An additional advantage of this method is its simplicity and availability.

6) Cost allocation by items

It is only the total cost, related to performing joint product manufacturing operations that is allocated. The charges associated with producing particular by-products should be included in the corresponding product cost. For example, the immediate expenditures on calf crop should include the following elements:

- Salary, including allowances for:
a) Calving;
b) Effective cow mating;
c) Rectal examination;
d) Calf labeling;

- Expenditures on cow mating;

- Cost of veterinary drugs;

- Artificial insemination centers keeping costs (depreciation, renovations to the premises, equipment repair, energy supply, heating, etc.); 
- Maternity barns keeping costs (depreciation, renovations to the premises, equipment repair, energy supply, heating, bedding cost, etc.).

Milk cost includes:

- Salaries, including allowances for milkers;

- Cost of keeping milking parlors;

- Cost of keeping milking equipment;

- Cost of abstergents and cleaning agents used while milking and washing milking equipment;

- Cost of keeping milk storage facilities and refrigerators.

Direct expenditure accounting provides the most substantive linkage between costs and calculated items, which gives a more valid production cost index for certain types of joint products. Conditional allocation of direct costs, involved in producing a certain product, gives substantially less reliable production cost figures for joint products.

\section{Conclusion}

We expect the proposed methods of calculating livestock product cost to solve the problems and largely improve the quality of information obtained. Although on a number of occasions use of these methods leads to more complicated computations and longer working hours, growing implementation of Management Information Systems for accounting in agro-industries will solve this problem.

\section{References}

Häsler B., Regula G., Stärk K.D.C., Sager H., Gottstein B., Reist M. Financial analysis of various strategies for the control of Neospora caninum in dairy cattle in Switzerland. Preventive Veterinary Medicine, 2006; 77(3-4): 230-253.

Hietala P., Wolfová M., Wolf J., Kantanen J., Juga J. Economic values of production and functional traits, including residual feed intake, in Finnish milk production. Journal of Dairy Science, 2014; 97(2): 1092-1106.

Meadows C., Rajala-Schultz P. J., Frazer G.S., Meiring R.W., Hoblet K.H. Evaluation of a contract breeding management program in Ohio dairy herds: Test day summary and economic measures. Animal Reproduction Science, 2008; 104(2-4): $189-200$.

Mohd Nor N., Steeneveld, W., Mourits M.C.M., Hogeveen H. Estimating the costs of rearing young dairy cattle in the Netherlands using a simulation model that accounts for uncertainty related to diseases. Preventive Veterinary Medicine, 2012; 106(3-4): 214-224.

Kalantari A.S., Cabrera V.E. The effect of reproductive performance on the dairy cattle herd value assessed by integrating a daily dynamic programming model with a daily Markov chain model. Journal of Dairy Science, 2012; 95(10): 6160-6170.

Belov N.G., Kostyanoy V.I., 1985, Accounting for agricultural enterprises. 2nd Ed. Agropromizdat, Moscow, pp. 368.

Ovrachenko E. 1975 Energy exchange at highly feed. VNIITEISKH, Moscow, pp. 68.

Berner X., Ketts H. A., 1973, Scientific bases of farm animals nutrition. Kolos, Moscow, pp. 376.

Eremin M. On calculation of costs and target prices in the cooperative cattle. Planning and accounting in agricultural enterprises, 1982; 11: $12-15$.

Nguyen C. Determination of the cost of litter in cattle. Agricultural Economics, 1981; 2: 91.

Belyi I.N., 1990, Calculation of production costs in agriculture. Graduate School, Minsk, pp. 176. 